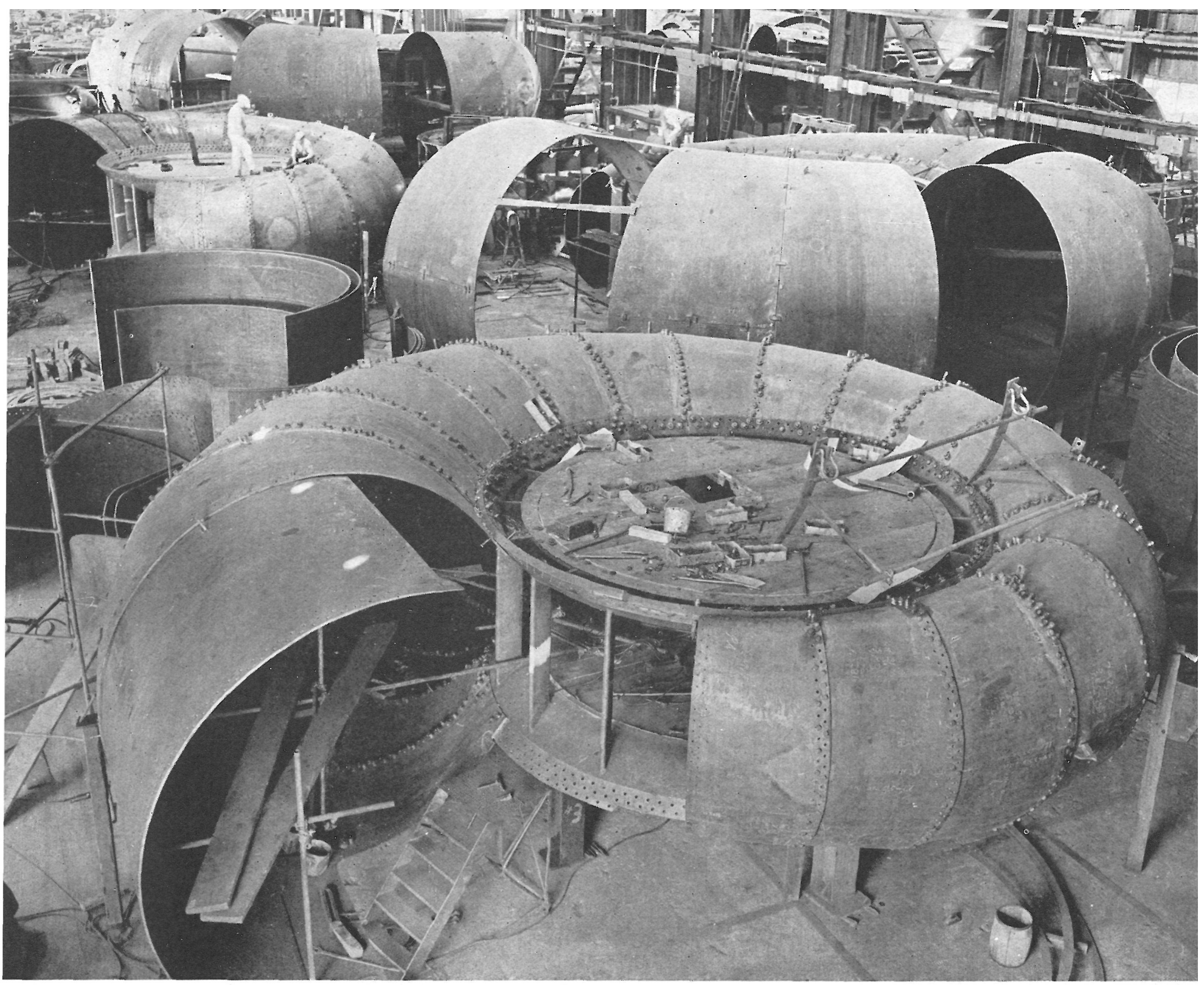

$532-12$

\title{
espirales tubulares para turbinas
}

Información amablemente facilitada por S. Morgan Smith Company, de York, Pensilvania (EE. UU.)

Para el suministro y fabricación de las espirales tubulares que debían alimentar las turbinas del aprovechamiento hidroéctrico de Brownlee, que constituye el primero de los cuatro saltos del grupo Hells Canyon, del río Snake, la conocida factoría S. Morgan Smith, especializada en la construcción de turbinas y material a ellas accesorio, se encargó del estudio, fabricación y montaje de cuatro de estas espirales tubulares de $5,50 \mathrm{~m}$ de diámetro máximo.

Las grandes dimensiones de este tipo de caparazón envolvente presentaba, en principio, una serie de graves inconvenientes de índole diferente. La deformación, transporte, montaje, chapa, espesor y costuras, así como la posibilidad de introducir las ventajas del amplio campo que se le olrece a la soldadura electrica en este tipo de construcciones metalicas, fue el tema de tendencia de cerrar las costuras entre chapas utilizando la soldadura eléctrica.

Aparte de las ventajas intrínsecas del propio procedimiento de la soldadura, su empleo mejora notablemente el régimen hidráulico del agua en el interior de estos caparazones, porque suprime solapes y resistencias perturbadcras de las cabezas de los remaches cuando las virolas se han roblonado.

A todas estas ventajas se opone, contrariamente, el delicado problema inherente a todo proceso de la soldadura; es decir, el estado tensional, tratamiento del material, deformaciones y tipo de electrodo, raiz, filete y preparación de labios para la de las razones que le condujeron a la solución final, de las que damos un ligero resumen.

Según dicha Memoria, la soldadura aventaja, económicamente, al roblonado. El acero empleado corrientemente es de bajo contenido de carbono y corresponde al definido en la norma A 285 del ASTM. El formado, calor, si es necesario, y la soldadura 


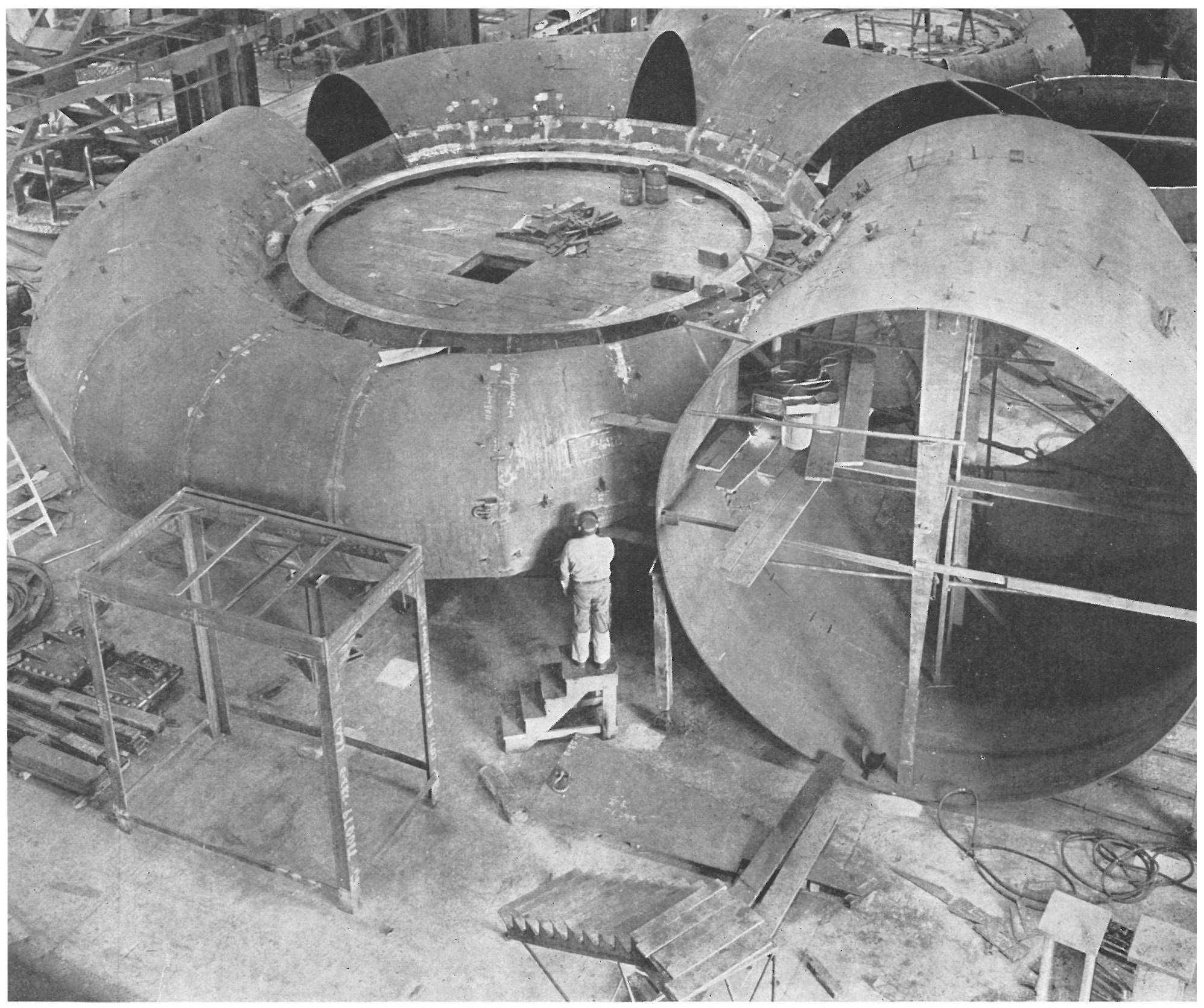

Fotos: S. MORGAN SMITH CO.

propiamente dicha no crean problema alguno. Los proyectos normales en los casos de grandes dimensiones daban espesores de más de $50 \mathrm{~mm}$, espesor que debía reducirse para facilitar todas las manipulaciones que experimenta la chapa y, por tanto, la chapa que ha de emplearse ha de tener un alto grado de resistencia.

Un nuevo tipo de acero, llamado "T-1», de alta resistencia sometido a un tratamiento térmico, con un límite elástico de $6.300 \mathrm{~kg} / \mathrm{cm}^{2}$ y tensión de rotura de 7.400 a $9.500 \mathrm{~kg} / \mathrm{cm}^{2}$, fué elegido para la construcción de estas espirales. Como en la obra sólo se ha de soldar entre chapas de «T-1», el metal no necesita un tratamiento térmico posterior para romper el estado tensional. Los espesores varían de 25 a $12 \mathrm{~mm}$, según los cálculos, para ciertas partes.

Las costuras se proyectaron de manera que se pudieran soldar operando de arriba hacia abajo en la medida de lo posible. Para la elección de electrodos se hicieron varios ensayos previos. El corte de la chapa con el soplete no presenta inconveniente, pero los labios de las costuras se pulimentaron convenientemente para evitar las capas de óxidos.

El formado de chapas se hizo en frío, con lo que se consiguió simplificar las operaciones de fabricación, ya que no se tenían que mandar las piezas formadas a parte alguna para su tratamiento térmico final. Se pudo experimentar que el cambio de la temperatura ambiente tenía sus consecuencias en la soldadura.

Después de ciertas experiencias se modificó el procedimiento de soldadura, en el que se calentaba la chapa de 120 a $150^{\circ} \mathrm{C}$, y se emplearon electrodos E $10016 \mathrm{MM}$. Estos electrodos se mantuvieron durante seis horas a la temperatura de $200^{\circ} \mathrm{C}$, no debiendo permanecer en el taller más de seis horas expuestos al ambiente.

Algunas partes soldadas en el taller se sometieron, después de soldar, a un tratamiento térmico, a $430^{\circ} \mathrm{C}$ de temperatura, con objeto de liberar el metal de tensiones. Todas las costuras se comprobaron por medio de rayos $\mathrm{x}$.

Debe tenerse en cuenta al hormigonar airededor de la espiral, que la elevada presión en el interior de las virolas de acero «T-1» provoca una deformación dos veces mayor a la equivalen:e a un acero dulce; por tanto, para evitar una carga excesiva en el hormigón bastará hormigonar con la espiral en plena carga o colocar una capa de material resilente en la mitad superior
de la espiral tubular. 